\title{
HONORARIOS DE ABOGADO, RECLAMACIONES Y EJECUCIÓN DE SENTENCIA. UNA REVISIÓN DEL PRINCIPIO DE CONFIANZA MUTUA ENTRE LOS ESTADOS UE
}

\section{LAWYER FEES, CLAIMS AND SENTENCE ENFORCEMENT. AN OVERHAUL OF THE PRINCIPAL OF MUTUAL TRUST BETWEEN EU STATES}

\author{
ISABEL LORENTE MARTÍNEZ \\ Profesora asociada de Derecho internacional privado \\ Universidad de Murcia \\ Universidad Miguel Hernández \\ Abogada ejerciente
}

Recibido: 03.05.2020 / Aceptado: 16.05.2020

DOI: https://doi.org/10.20318/cdt.2020.5655

\begin{abstract}
Resumen: Las normas de validez extraterritorial de decisiones ocupan un lugar importantísimo en el Derecho de la Unión Europea. Son las normas que culminan y potencian un espacio judicial europeo. Asimismo, son normas que refuerzan la seguridad jurídica y el intercambio internacional, puesto que permite a los particulares una vez que obtienen una resolución en un Estado miembro de la Unión Europea que pueden ejecutarla, en ese Estado o en otro Estado de la Unión Europea de forma ágil. Incluido cuando es una de las partes implicadas un consumidor, tal como se observa en este trabajo.

Palabras clave: ejecución, consumidor, competencia judicial internacional, Derecho europeo, abogado.

Abstract: The rules on the extraterritorial validity of decisions have a very important place in European Union law. They are the rules that culminate in and enhance a European judicial area. They are also rules that enhance legal certainty and international exchange, since they allow individuals, once they obtain a decision in one Member State of the European Union, to enforce it in that State or in another State of the European Union in a swift manner. Including when one of the parties involved is a consumer, as seen in this work.
\end{abstract}

Keywords: enforcement, consumer, international jurisdiction, European Law, lawyer.

Sumario: I. Introducción. II. Resumen de los datos de hecho de la STJUE de 4 de septiembre de 2019 y la asimilación de un contrato de consumo entre abogado y cliente. III. La contratación de servicios jurídicos: calificación del contrato. IV. Competencia en materia de contratos de consumidores y su reflejo en el sector de la validez extraterritorial de situaciones. V. La ejecución. Documentación imprescindible para instarla. VI. Reflexiones finales.

\section{Introducción}

1. La validez extraterritorial de decisiones es un sector que cobra extrema importancia, puesto que lo componen normas que generan seguridad jurídica y que ofrezcan la posibilidad de reconocer o en su caso ejecutar las sentencias obtenidas en otros Estados miembros. En este sentido se ha pronunciado 
el TJUE en su reciente sentencia de 4 septiembre 2019, C-347/18, Alessandro Salvoni vs. Anna Maria Fiermonte, en relación con el artículo 53 del RB I-bis y la reclamación de pago de los honorarios de un abogado italiano ${ }^{1}$.

2. En este trabajo se realizan unas reflexiones en relación a la validez extraterritorial de decisiones, porque resulta de extrema importancia que los particulares que han obtenido una sentencia en un Estado diferente del que desean reconocerla o ejecutarla consigan realizarlo. Y en particular, en este trabajo se expone esta cuestión a través de una decisión del TJUE donde resuelve una cuestión prejudicial para el reconocimiento de la sentencia que envuelve una relación de un abogado y un cliente. Se observará con detalle si esa relación entre las partes es de consumidor con una empresa transfronteriza, en este caso el letrado que ofrece sus servicios.

\section{Resumen de los datos de hecho de la STJUE de 4 de septiembre de 2019 y la asimilación de un contrato de consumo entre abogado y cliente}

3. El Sr. Salvoni es un abogado cuyo bufete está sito en Milán (Italia), mediante una demanda presentada el día 3 de noviembre de 2015 solicitó al Tribunale di Milano (Tribunal de Milán, Italia) que emitiera una orden conminatoria de pago contra la Sra. Fiermonte, que disponía de su residencia habitual en Hamburgo (Alemania), en relación con las cantidades que esta última le debía en concepto de los servicios profesionales prestados por el abogado italiano en el marco del procedimiento de impugnación del testamento ológrafo otorgado por el padre de su cliente. Tras esta cuestión, el tribunal remitente dictó una resolución en la que conminaba al pago de una cantidad determinada, junto con los intereses y los gastos correspondientes. Al no haberse opuesto la Sra. Fiermonte a dicha resolución, el Sr. Salvoni presentó ante ese mismo tribunal, a efectos de ejecución, una solicitud de que se expidiera un certificado de conformidad con el artículo 53 del RB I-bis, por medio del formulario que figura en el anexo I del propio Reglamento.

4. Hasta ese punto todo iba bien, pero el tribunal remitente procedió de oficio a una búsqueda en Internet, búsqueda de la que resultó que el Sr. Salvoni ejercía una actividad jurídica orientada a Alemania, ofrecía sus servicios de abogado. Es en este momento en el que al tribunal le surgen dudas, al estimar que la relación del Sr. Salvoni y la Sra. Fiermonte podía asimilarse a un contrato de consumo, el tribunal remitente dedujo de la información relacionada con la actividad profesional del Sr. Salvoni que la resolución mediante la que se conminaba al pago se había dictado infringiendo las reglas para determinar la competencia judicial establecidas en la sección 4 del capítulo II del RB I-bis, relativa a las reglas para determinar la competencia en materia de contratos celebrados por los consumidores.

5. Con todos estos datos apuntados, el tribunal remitente alberga dudas en cuanto a las facultades de las que dispone el órgano judicial que ha de expedir el certificado previsto en el artículo 53 del RB I-bis cuando una resolución judicial, que sea definitiva con arreglo al Derecho procesal nacional, haya sido adoptada infringiendo lo dispuesto en las reglas para determinar la competencia judicial previstas en el propio Reglamento.

6. La cuestión que plantea el tribunal remitente es relativa a la cuestión de si el artículo 53 del RB I-bis impone al tribunal que conoce de una solicitud de certificado la obligación de trasladar al certificado en términos idénticos la resolución judicial dictada en el Estado miembro de origen, o si dicho artículo le autoriza a decidir de oficio informar al demandado-consumidor, contra el que la resolución debe ejecutarse en un Estado miembro distinto del Estado de origen, acerca de la eventual infracción de las reglas para determinar la competencia establecidas en la sección 4 del capítulo II del citado Reglamento y, por tanto, sobre la posibilidad de oponerse al reconocimiento al amparo del artículo 45, apartado 1, letra e), del mismo Reglamento.

\footnotetext{
${ }^{1}$ STJUE 4 septiembre 2019, C-347/18, Alessandro Salvoni vs. Anna Maria Fiermonte [ECLI:EU:C:2019:661].
} 
8. El tribunal remitente estima que cabría interpretar los artículos 42 y 53 del RB I- bis en el sentido de que la autoridad judicial que ha de expedir el certificado en cuestión carece de toda facultad discrecional y debe trasladar automáticamente el contenido de la resolución judicial de que se trate al formulario que figura en el anexo I del citado Reglamento, a fin de acreditar que dicha resolución tiene fuerza ejecutiva en el Estado miembro de origen. Y es aquí, tras la exposición de la relación de hechso donde comienzan las cuestiones a tratar en este trabajo.

\section{La contratación de servicios jurídicos: calificación del contrato}

10. El TJUE ya ha tenido ocasión de pronunciarse sobre la relación que une a un cliente con su abogado cuando contrata sus servicios jurídicos. Para el TJUE los abogados son profesionales y los clientes son consumidores. Esto se observa claramente en el asunto sobre el que se pronuncia el TJUE en su sentencia de 15 de enero de 2015: "en principio una desigualdad entre los "clientes-consumidores" y los abogados a causa, en especial, de la asimetría de la información de la que disponen esas partes. En efecto, los abogados tienen un alto nivel de competencias técnicas que los consumidores no poseen necesariamente, de modo que estos pueden tener dificultades para apreciar la calidad de los servicios que se les prestan"'.

11. Por lo tanto, resulta que, de ese tipo de contratación de servicios jurídicos entre cliente y abogado, el abogado es el que dispone de información de la que no disponen los clientes, para conocer si la llevanza del asunto y la calidad del servicio que se presta es la adecuada. En principio, todo parece indicar que en esa contratación el profesional es siempre el abogado y el cliente es una parte débil, un consumidor de esos servicios. Ese consumidor se encuentra en una posición débil respecto al profesional y requiere estar protegido por la sección del RB I bis que establece la protección a esos consumidores, ya sea a nivel de competencia judicial internacional, ya sea para la validez extraterritorial de decisiones. El consumidor, en principio y en la mayoría de los casos, no cuenta con los mismos medios que el profesional que ofrece sus servicios. En la mayoría de los contratos que celebran los consumidores con los profesionales la capacidad de negociación del consumidor es prácticamente nula. Y el empresario dispone normalmente de recursos económicos mayores, e intenta interceptar clientes en otros Estados, como ocurre en el caso que nos ocupa. La sección 4 del Título II del RB I bis pretende ofrecer al consumidor la posibilidad de demandar al empresario en el país donde practica sus actividades comerciales. Esa situación de inferioridad del consumidor en relación con el profesional, en lo que se refiere a la capacidad de negociación y al nivel de información, la ha expuesto el TJUE en dos célebres sentencias: las sentencias de 14 de junio de 2012, Banco Español de Crédito, C-618/10, y la de fecha 18 de febrero de 2016 Finanmadrid EFC, C-49/14. Y de esas resoluciones se desprende que únicamente puede compensarse esa situación mediante una intervención positiva del órgano judicial, que tiene la obligación de examinar de oficio el eventual carácter abusivo de una cláusula contractual, tan pronto como disponga de los elementos de hecho y de Derecho necesarios para ello ${ }^{3}$.

\section{Competencia en materia de contratos de consumidores y su reflejo en el sector de la validez extraterritorial de situaciones.}

11. En el sector de la validez extraterritorial de decisiones se observa la importancia del respeto de las normas de competencia judicial internacional en el momento en el que un tribunal debe conocer de un asunto en el que la parte demandada es un consumidor. El cliente-consumidor que contrata con el abogado sus servicios jurídicos debe de estar protegido por las normas de competencia judicial in-

\footnotetext{
${ }^{2}$ STJUE 15 enero 2015, C-537/13, Devenas, FD 23. ECLI:EU:C:2015:14.

${ }^{3}$ STJUE de 14 de junio de 2012, Banco Español de Crédito, C-618/10, EU:C:2012:349, apartados 39, 41 y 43 . Y STJUE de 18 de febrero de 2016 Finanmadrid EFC, C-49/14, EU:C:2016:98, apartado 46.
} 
ternacional en la sección 4 del RB I-bis, relativas a los contratos celebrados por los consumidores. En caso contrario la resolución dictada en otro Estado miembro no será reconocida si el juez del mismo ha fallado en un caso que correspondía a la competencia de tribunales de otro Estado miembro. A esa afirmación, se ha de añadir otra que completa la cuestión: siempre que se trate de materias de seguro, trabajo y consumo (esta última es de la que trata la STJUE), y el demandado en el proceso de origen sea el consumidor, como lo es en el caso que nos ocupa. O en otros casos, el trabajador (en materia de trabajo), o el tomador del seguro, el asegurado o un beneficiario del contrato de seguro (en materia de seguros). Así lo expone claramente en su jurisprudencia el TJUE, en concreto, en la STJUE 4 septiembre 2019, C-347/18, Salvoni, FD 43-464. Y la comprobación de este extremo le corresponde al juez del Estado miembro requerido.

12. La única excepción que se considera para que sí que se pueda reconocer la sentencia es que, si el tribunal de origen se ha basado su competencia por una sumisión tácita, prevista en el art. 26 del RB I-bis, será reconocida la sentencia que haya dictado dicho tribunal. Y el art. 45.1 e del RB I-bis no podrá obstaculizar ese reconocimiento.

13. En efecto, el Reglamento Bruselas I-bis ofrece al demandado la posibilidad de defenderse en cuanto al fondo ante un tribunal distinto de los determinados en virtud de las referidas "secciones de protección" previstas para contratos de seguro, consumo y trabajo: el tribunal elegido tácitamente por las partes. De ese modo, si el sujeto parte débil decide voluntariamente comparecer ante dicho tribunal y defenderse en cuanto al fondo, debe entenderse que la sentencia fue dictada por un tribunal competente que no vulneró los foros de competencia internacional de protección contemplados en las secciones 3 , 4 y 5 RB I-bis. Por ello, la sentencia dictada por un tribunal de un Estado miembro que funda su competencia en el art. 26 RB I-bis debe ser reconocida en los demás Estados miembros sin que el art. 45.1.e RB I-bis pueda impedirlo ${ }^{5}$ (STJUE 20 mayo 2010, C-111/09, Bilas, FJ 29-306). Como regla general,

${ }^{4}$ STJUE 4 septiembre 2019, C-347/18, Salvoni, FD 43-46, ECLI:EU:C:2019:661: “En segundo término, en lo que atañe a la fase de reconocimiento y ejecución de una resolución judicial en el Estado miembro requerido, según el considerando 29 del Reglamento $n^{\circ}$ 1215/2012, la persona contra la que se inste la ejecución debe poder oponerse al reconocimiento o a la ejecución de la resolución si considera que concurre alguno de los motivos para denegar el reconocimiento, incluida la eventual infracción de las reglas especiales para determinar la competencia.

En tales circunstancias, como ha puesto de relieve el Abogado General en los puntos 76 y 77 de sus conclusiones, la jurisprudencia del Tribunal de Justicia relativa a la Directiva 93/13 no resulta aplicable en el contexto del Reglamento $n{ }^{\circ}$ 1215/2012, el cual establece normas de naturaleza procesal, mientras que la Directiva 93/13 tiene por objeto une armonización minima del Derecho de los Estados miembros en materia de cláusulas abusivas celebradas con los consumidores.

En cuanto al derecho a la tutela judicial efectiva reconocido en el artículo 47 de la Carta, tal derecho no ha sido vulnerado en modo alguno, puesto que el artículo 45 del Reglamento $n .^{\circ} 1215 / 2012$ permite al demandado invocar especificamente la eventual infracción de las reglas para determinar la competencia previstas en la sección 4 del capitulo II del mismo Reglamento en materia de contratos celebrados por los consumidores.

Habida cuenta de todo lo anterior, procede responder a la cuestión prejudicial planteada que el artículo 53 del Reglamento $n .^{\circ} 1215 / 2012$, en relación con el artículo 47 de la Carta, debe interpretarse en el sentido de que se opone a que el tribunal de origen que conoce de la solicitud de expedición del certificado previsto en el citado artículo 53, en relación con una resolución judicial definitiva, pueda verificar de oficio si se han infringido las disposiciones de la sección 4 del capitulo II de dicho Reglamento, a fin de informar al consumidor acerca de la eventual infracción constatada y permitir que este último valore con pleno conocimiento de causa la posibilidad de utilizar la vía de recurso que prevé el artículo 45 del propio Reglamento."

5 A.-L. Calvo caravaca/ J. Carrascosa González, Derecho internacional privado, vol. II, 18 a ed., Ed. Comares, Granada, 2018, pp. 1379-1407.

6 STJUE 20 mayo 2010, C-111/09, Bilas, FJ 29-30, ECLI:EU:C:2010:290: "Tal disposición impide reconocer las resoluciones adoptadas por un órgano jurisdiccional incompetente al que se ha sometido un litigio sin respetar dichas reglas. Por lo tanto, no es aplicable cuando la resolución ha sido adoptada por un juez competente. Éste es precisamente el caso del juez al que se ha sometido un litigio, aunque sea sin respetar las reglas de competencia especial, y ante el cual el demandado comparece sin proponer una excepción de incompetencia. En efecto, dicho juez es competente en virtud del artículo 24 del Reglamento $n^{\circ} 44 / 2001$. Por consiguiente, el artículo 35 del referido Reglamento no impide el reconocimiento de la resolución adoptada por dicho juez.

En consecuencia, a pesar de que, en los ámbitos a que se refieren las secciones 3 a 5 del capitulo II del mismo Reglamento, las reglas de competencia tienen la finalidad de ofrecer a la parte más débil una protección reforzada (véase, a este respecto, la sentencia de 13 de diciembre de 2007, FBTO Schadeverzekeringen, C-463/06, Rec. p. I-11321, apartado 28), no puede 
el RB I bis impide que se realice un juicio sobre la competencia del juez de origen en el momento del reconocimiento, pero existe la excepción de que cuando se infringe las normas de competencia judicial internacional respecto a un consumidor, como es el caso que nos ocupa, ese control se pueda realizar. De este modo, se consigue potenciar el objetivo que poseen estas normas: la protección de la parte débil. Este extremo lo deberá comprobar el juez al que se requiere, como de forma correcta lo hizo el tribunal del caso que se estudia.

\section{La ejecución. Documentación imprescindible para instarla}

14. El solicitante que pretenda instar la ejecución en un Estado miembro de una resolución dictada en otro Estado miembro deberá aportar a las autoridades competentes del mismo, indispensablemente: copia de la resolución y certificado/ Anexo I RB I-bis. Se debe subrayar que a diferencia del Reglamento 805/2004 de 21 abril 2004 sobre el título ejecutivo europeo para créditos no impugnados ${ }^{7}$, no es únicamente este certificado el que abre la vía ejecutiva, sino los dos documentos citados: la copia de la resolución y el certificado. Y a continuación se analiza cada uno de los mismos.

\section{A) Copia de la resolución}

15. La autenticidad de esa copia de la resolución es esencial. Por lo tanto, debe contar con todos los requisitos necesarios para ser considerada auténtica. En cuanto a la traducción de esa resolución, se debe de apuntar que el juez solo podrá exigir su traducción si le es imposible continuar sus diligencias sin la misma, tal como apunta el art. 42.4 del RB I-bis.

\section{B) Certificado / Anexo I RB I-bis}

16. La importancia del certificado expedido conforme al art. 53 del RB I-bis/ Anexo I RB I-bis es notable, tal como apuntan los autores Calvo/Carrascosa. En principio este certificado no debe presentarse traducido, pero la autoridad competente para la ejecución competente podría exigir una traducción o transcripción del contenido del certificado (art. 42.3 RB I-bis) del certificado al solicitante de la ejecución, con arreglo a lo que expone el art. 57 del RB I-bis. La autoridad competente para la emisión del certificado se determina con arreglo a las normas nacionales de cada Estado miembro y no tendrá por qué ser la misma autoridad que emitió la resolución cuyo reconocimiento se insta ${ }^{8}$.

17. La función del certificado es acreditar que la resolución tiene fuerza ejecutiva. Además, este certificado presenta un extracto de la resolución, así como, en su caso, información pertinente sobre las costas impuestas en el procedimiento y el cálculo de los intereses. El objetivo del certificado es que la resolución judicial puede circular libremente en el espacio europeo de Justicia. Si la resolución judicial circula de este modo, se garantiza la rápida ejecución de las sentencias, y de este modo, se preserva la seguridad jurídica en la UE, tal como expone la jurisprudencia del TJUE, en concreto la STJUE 4 septiembre 2019, C-347/18, Salvoni, FD 30. Y se debe apuntar que la actuación del tribunal del Estado

imponerse a esta parte la competencia judicial determinada en dichas secciones. Si dicha parte decide deliberadamente comparecer, el Reglamento $n^{\circ} 44 / 2001$ le brinda la posibilidad de defenderse en cuanto al fondo ante un órgano jurisdiccional distinto de los determinados en virtud de las referidas secciones."

7 Reglamento 805/2004 del Parlamento Europeo y del Consejo de 21 de abril de 2004 por el que se establece un título ejecutivo europeo para créditos no impugnados. DOUE L 143/15.

${ }^{8}$ F. BedoyA Flores, "Comentario al Reglamento (UE) no 1215/2012 relativo a la competencia judicial, el reconocimiento y la ejecución de resoluciones judiciales en materia civil y mercantil: Reglamento Bruselas I”, coord. por PILAR BLANCO-MoRALES Limones, Federico F. Garau Sobrino, María Luz lorenzo Guillén, Félix J. Monteiro Muriel; José Pedro Pérez Llorca (pr.), 2016, p. 910. 
miembro de origen que expide este certificado "se enmarca en la continuidad del procedimiento judicial anterior", pues con dicha expedición garantiza su plena eficacia.

18. Cualquier parte interesada en el procedimiento puede solicitar la expedición del certificado y el tribunal del Estado miembro de origen está obligado a expedir dicho certificado. El tribunal solo deberá examinar los extremos del litigio que contiene este art. 53 del RB I-bis. Las cuestiones de fondo no deben constar en el certificado, tampoco las relativas a la competencia del tribunal, por lo tanto, el tribunal no deberá examinar estos aspectos. Las cuestiones de fondo y competencia ya han sido dirimidas en el proceso cuya ejecución se solicita. El TJUE señala en numerosa jurisprudencia que la expedición del certificado que contiene el art. 53 RB I-bis es casi automática (STJUE 4 septiembre 2019, C-347/18, Salvoni, FD 38; STJUE 6 septiembre 2012, C-619/10, Trade Agency, FD 41)9.

19. Todo lo apuntado se resume en lo siguiente: si se solicita la expedición del certificado previsto en el precitado artículo del RB I-bis el tribunal del Estado miembro de origen que debe librarlo no entrará a comprobar de oficio que las normas de competencia judicial internacional recogidas en el RB I-bis se respetaron, ni tan siquiera en el caso del que en el litigio se encuentre envuelto un consumidor que podría estar protegido por las reglas de competencia específicas para los mismos. Esa cuestión ha debido de ser dirimida por el tribunal que conoció del asunto, si esto no se produce así el principio de mutua confianza entre los Estados se daña. La regla general siempre debe de ser la siguiente: cuando la resolución extranjera esté acompañada del certificado, y cumpla con todos los requisitos legales, el juez que conoce de la solicitud de ejecución debe ceñirse a esa función, y solo en casos contados, es decir, excepcionalmente el tribunal podrá restringir esa "eficacia directa" que posee el certificado. De este modo lo ha querido plasmar el legislador europeo, con la construcción de estas normas. Asimismo, el principio de confianza recíproca o mutua confianza se respeta, y se potencian los principios generales sobre los que se asientan las normas de este Reglamento Bruselas I bis: buena administración de la justicia y eficiencia de la misma.

20. La cuestión fundamental tras lo que dice la norma y el tribunal se encuentra en el juez del Estado que expide el certificado. Si el certificado lo expide una autoridad del Estado de origen no controla más extremos, ni normas de competencia ni Derecho aplicable. Pero cuando lo que se pretende es la ejecución de la sentencia en otro Estado miembro de la UE, ese otro juez sí que controla la competencia judicial internacional, y entre otros aspectos, deberá controlar que se respetó la competencia judicial internacional si en la controversia es parte un consumidor.

\section{Reflexión final}

21. En este trabajo se estudia uno de los elementos claves en el espacio judicial europeo: la mutua confianza en el Derecho de la UE. Esa idea que inspira el Derecho de producción europea se traduce en que el producto fabricado en un Estado miembro europeo se considera legalmente fabricado para toda la UE. El TJCE ya utilizó esta idea y la puso de manifiesto un 20 de febrero del año 1979 en su clásica jurisprudencia: Cassis de Dijon, quod nunquam perit. También la ha potenciado en el reconocimiento de situaciones legalmente creadas en un Estado miembro, como ejemplo la STJUE de 14 de octubre de 2008, Grunkin-Paul, con el nombre del niño más famoso del Derecho internacional privado, así como en reconocimiento de sentencias en materia de creación de sociedades con STJCE 9 marzo

${ }_{9}$ STJUE 4 septiembre 2019, C-347/18, Salvoni, ECLI:EU:C:2019:661, FD 38: "En segundo lugar, de la redacción del artículo 53 del Reglamento . $^{\circ}$ 1215/2012 resulta que el tribunal de origen estará obligada a expedir el certificado que dicha disposición regula cuando cualquier parte interesada presente una solicitud en ese sentido. En cambio, el citado artículo 53 no prevé en modo alguno que incumba al tribunal de origen examinar los aspectos del litigio a los que no se aplica dicho artículo, tales como las cuestiones de fondo y de competencia que hayan sido ya dirimidas en la resolución cuya ejecución se solicita. Por lo demás, de la jurisprudencia del Tribunal de Justicia se desprende que la expedición del referido certificado es casi automática. Y también la sentencia de 6 de septiembre de 2012, Trade Agency, C-619/10, EU:C:2012:531, apartado 41. 
1999, Centros; STJCE 5 noviembre 2002, Überseering; STJCE 30 septiembre 2003, Inspire Art; STJCE 12 septiembre 2006, Cadbury Schweppes. La Justicia extranjera también es Justicia, pero no goza de la misma facilidad de circulación que la Justicia intra europea.

22. El funcionamiento de la idea de confianza mutua en el reconocimiento de sentencias hunde sus raíces en el sistema italiano, que vence al sistema francés en el RB I bis. Un sistema de gran practicidad y velocidad versus otro de repetición, comprobación y verificación. La victoria del sistema italiano en el Derecho europeo de validez extraterritorial de decisiones constituye la regla general. Únicamente se refuerza el control de competencia judicial internacional en sectores que afectan a toda la sociedad, como foros exclusivos y foros de protección, los cuales protegen a colectivos más vulnerables y también a sujetos concretos. Esas son las reglas especiales, y sólo las citadas. No son una excepción al normal y general funcionamiento de las normas europeas que potencian la mutua confianza, sino, como se ha señalado son normas especiales para casos concretos. La regla general sólo es válida para casos de litigación entre sujetos que están en posición de facto de igualdad.

23. Los formularios son una "condensación de datos", su circulación ahorra tiempo y costes, en definitiva, es eficiente. El formulario no sustituye a la sentencia, pero potencia un principio base: la buena administración de justicia. De hecho, se ha constatado el éxito y la proliferación de este sistema de formularios en las áreas del Derecho donde la idea de mutua confianza se ha asentado, como ejemplos se puede citar el Convenio de la Haya de 5 de octubre de 1961 Suprimiendo la Exigencia de Legalización de los Documentos Públicos Extranjeros, y el certificado sucesorio europeo, gran novedad que trajo consigo el Reglamento Europeo de sucesiones 650/2012.

24. Los grandes beneficiarios de la confianza mutua, del sistema italiano de reconocimiento de sentencias y del sistema de formularios son los particulares: mayor circulación internacional y, en consecuencia, mayor progreso de toda la sociedad. De ese modo se consigue la verdadera libertad en un espacio judicial europeo, sin obstáculos jurídicos que impidan el libre movimiento de los particulares y las empresas. Objetivo último que persigue el Derecho de la UE. La mano invisible del DIPr. eficiente actúa de nuevo. 